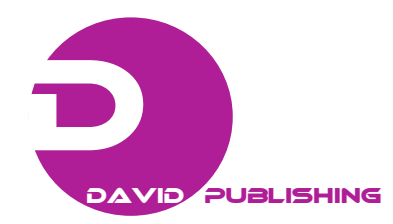

\title{
PEF Assisted Thermal Sterilization (PEF-ATS) Process-Inactivation of Geobacillus sterothermophilus
} \section{Spores}

\author{
Sally R. Alkhafaji and Mohammed M. Farid \\ Department of Chemical \& Materials Engineering, The University of Auckland, Private Bag 92019, Auckland, New Zealand
}

Received: March 13, 2012 / Published: July 20, 2012.

\begin{abstract}
An improvement to existed methods of microbial spore inactivation is presented in this paper. A treatment chamber was designed to hold elevated temperatures (above $100{ }^{\circ} \mathrm{C}$ ) and pressure in the range of ( $3 \mathrm{~atm}$ ). The innovative thermal assisted pulsed electric fields (PEF-ATS) processing was applied to inactivate Geobacillus sterothermophilus ATCC 10149 spores suspended in simulated milk ultrafiltrate (SMUF) of 50\% (wt/wt) concentration. G. stearothermophilus spores are extremely resistant to high temperature and are also proven to be resistant to PEF processing in the range of $35 \mathrm{kv} / \mathrm{cm}$. However, the combination of PEF and high temperature treatment conducted in this work shows significant inactivation of the G. stearothermophilus spores. A processing temperature/time of $115{ }^{\circ} \mathrm{C} / 3.7 \mathrm{sec}$ with an electric field intensity of $45 \mathrm{kv} / \mathrm{cm}$ showed 4.1 logmicrobial reductions, which are significantly less than usually obtained in thermal treatment alone.
\end{abstract}

Key words: PEF-ATS, spores inactivation, G. stearothermophilus, spores.

\section{Introduction}

Thermal inactivation of bacterial spores has been the topic of many studies due to their high heat resistance. Thermophilic sporeformers play an important role in spoilage of milk and milk products. Thermophilic bacteria, in particular the $G$. stearothermophilus have been employed as an indicator for monitoring the thermal sterilization processes [1, 2]. TeGiffel et al. [3] found that several species belonging to the genus Bacillus, Aneurinibacillus and Paenibacillus which were also able to withstand temperatures above $120^{\circ} \mathrm{C}$.

Since many products can not withstand the heat treatment required to inactivate the thermophilic bacterial spores, alternative methods are required to inactivate the thermophilic microorganisms without affecting flavour, taste and nutrientsin food. PEF

Corresponding author: Mohammed M. Farid, professor, research fields: chemical and materials engineering, FIChemE. E-mail:m.farid@auckland.ac.nz. technology has received great attention as an alternative to the traditional thermal processing during the last decade. The PEF processing can effectively inactivate vegetative microbial cells; however, bacterial spores which could cause danger to human health are the most resistant to PEF treatment. Numerous studies have been published that indicate the dependence of the lethal effect of PEF pulses on the shape and size of the microbes $[4,5]$.

Spores structure is different and more complex compared to that of vegetative cells and their size is smaller. The size and shape of microorganism play an important role on the sensitivity to the PEF treatment. This can be explained as the induced voltage across the cell membrane which is proportional to the geometric size of the cell. When external electric field of short duration applied, an imposed transmembrane potential above a critical electric field intensity will be induced, which may produce a dramatic increase of the microbial membrane permeability as well as exchange 
or loss of cell contents. Cell lysis and irreversible destruction may occur as secondary mechanisms. This will limit the ability of cells to repair themselves, which adversely affect permeable cells through osmotic pressure differences between the medium and the interior of the cell. The induced potential is greater in a large cell, which means larger cells are more susceptible to damage than small cells [6].

Numerous researchers have been applying pulsed electric field processing to different food products containing spores without/or with minor heating [7-9], they reported that the spores were resistant to the pulsed electric fields treatment at moderate temperatures. Yin, Zhang \& Sastry [9] reported that PEF processing has limited effect on microbial spores due to the spores rigid structure and their ability to resist the unfavourable environmental conditions. They suggested that the inactivation rate of spores decreased as pulse frequency increased. Although increasing pulse frequency increases treatment time, there seems to be an optimal PEF treatment frequency that may cause resonance of the bacterial spore structure. This resonance causes a loosening of the rigid bacterial spore structure such that the applied pulse electric field punch through the spore structure and inactivate the spores.

The objective of the work presented in this paper is to demonstrate the potential of applying PEF-ATS processing to enhance the inactivation of Geobacillus stearothermophilus spores, which were found resistant to both PEF and thermal treatments if applied separately. The suspending media inoculated with these spores was subjected to the PEF pulses at elevated temperatures for a very short time comparing to the time/temperature using thermal pasteurisation. The process parameters were selected to ensure processing temperature and treatment time below thermal processing.

\section{Materials and Methods}

\subsection{Microbial Spores}

Geobacillus sterothermophilus ATCC 10149 spores suspended in saline water were obtained from Fort Richard lab Ltd. in glass vials. In all experiments, the initial concentration of the spores in the suspending medium was approximately $1 \times 10^{7} \mathrm{cfu} / \mathrm{mL}$. Samples of the untreated and treated suspensions were analysed for microbial concentration using the BacTrac measuring instrument (SY-LAB Instrument $\mathrm{GmbH}$ ), where the microbial detection is based on impedance splitting method. The microbial metabolism utilises nutrient and produced lower molecular compounds, which alter the conductivity of liquid nutrients and lower their electrical impedance, which can be measured using two electrodes in the nutrient solution. The BacTrac measuring technology is based precisely on this principle, whereby the time lapse of the alteration of the ionic composition in the nutrient was recorded. A relationship between Colony Forming Unit (CFU) and BacTrac Impedance Detection Time $(t)$ for a calibrated BacTrac application using linear regression was established. A calibration was produced using 30 samples of the suspension (SMUF) with different concentration of Geobacillus sterothermophilus ATCC 10149 spores. The microbial load in these samples was measured using the plate count method as the reference method against the impedance method. For further details of the procedure authors refer to the publication of Alkhafaji and Farid [10].

\subsection{Suspending Media}

The composition of the SMUF used in this work was mentioned by Pothakamury, Monsalve-Gonzalez, Barbosa-Ca`novas \& Swanson [11], and is shown in Table 1. SMUF was diluted with deionised water to concentration of $50 \%$ (wt/wt), to provide testing fluids with electrical conductivity of $2.47 \mathrm{mS}$.

\subsection{The PEF Unit}

The PEF unit (Fig. 1) used in this work is a modified unit of the innovative PEF unit described by Alkhafaji \& Farid [10]. The modified treatment chamber 

Geobacillus sterothermophlis Spores

Table 1 Simulated milk ultra filtrate (Pothakamury, Monsalve-Gonzalez, Barbosa-Ca`novas \& Swanson) [12].

\begin{tabular}{ll}
\hline Components & $\begin{array}{l}\text { Concentration } \\
\text { (g/L distilled water) }\end{array}$ \\
\hline Lactose & 50.00 \\
Potassium phosphate monobasic & 1.58 \\
Tripotassium citrate & 0.98 \\
Trisodium citrate & 1.79 \\
Potassium sulphate & 0.18 \\
Calcium chloride dehydrate & 1.32 \\
Magnesium citrate & 0.38 \\
Potassium carbonate & 0.30 \\
Potassium chloride & 1.08 \\
Potassium chloride & 1.08 \\
\hline
\end{tabular}

(Fig. 2a) was designed to hold operating temperatures above $100{ }^{\circ} \mathrm{C}$ and pressure of $3 \mathrm{~atm}$. The chamber is made of Teflon which can hold temperature up to $260{ }^{\circ} \mathrm{C}$ without deforming. Operating at this pressure is important to prevent local evaporation of the liquid under investigation at elevated temperatures. The chamber was designed as one solid part including the treatment zone in order to hold the pressure of 3 atm without causing leakage of the product, with two stainless steel prostrated disk, electrodes isolated from each other by an insulator element designed to form an orifice where the voltage across the orifice is close to the supplied voltage. Each disk electrode is of $54 \mathrm{~mm}$ diameter and includes 148 pores, each pore is of $1.5 \mathrm{~mm}$. The chamber further includes two separate parts that configured to form the inlet and outlet ports. The cross sectional area and depth of the orifice were determined to minimise voltage loss in the outlet and inlet regions of the treatment chamber. The electrodes are placed apart from the treatment region to prevent electrical tracking through the insulator surface and also to prevent local field enhancements in the treatment chamber. Uniform electric field distribution was achieved by removing the interface between the electrodes, insulator, and the product from the high field region, which also avoids to foul of the electrodes. The dimensions of the treatment chamber were selected based on previous intensive studies on the treatment chamber designed by Alkhafaji [13]. Fibre optic temperature sensors connected to the treatment chamber were used to measure the temperature. Degassing of the liquid food was conducted prior to processing to prevent the possibility of dielectric breakdown within the treated liquid. The presence of gas bubbles in the liquid food may cause the electric field magnitude to decrease significantly near the boundary of the bubble, thus threatening the uniformity of the PEF treatment across the chamber gap. The degassing unit includes pressure gauges and a vacuum pump.

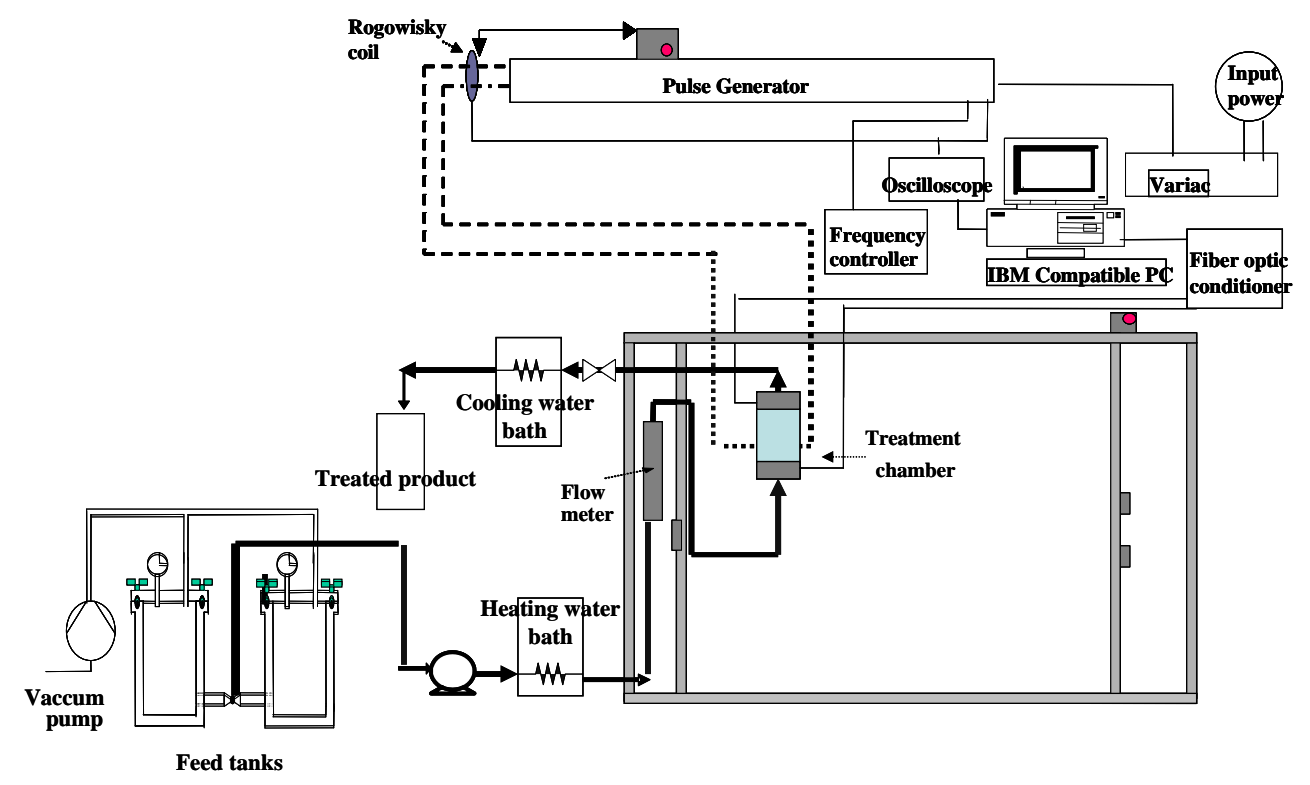

Fig. 1 The TAPEF unit (The University of Auckland). 


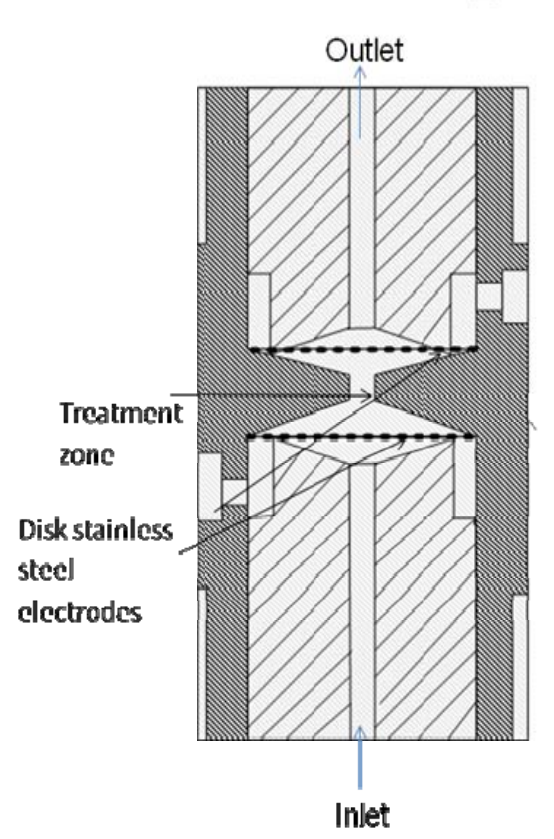

Fig. 2 The TAPEF treatment chamber (The University of Auckland).

The high voltage pulse generator (Fig. 3) used in this work provides high voltage up to $30 \mathrm{kV}$ and square bipolar pulses of $1.7 \mu$ duration with very short pulse rising and falling times of less than $0.5 \mu \mathrm{s}$ and frequency up to $1,000 \mathrm{~Hz}$. The short rising time increases the efficiency of the PEF treatment. Most of the power supplied is utilised for microbial inactivation with minimum heating [14]. The pulses generated in this work maintain a pulse with a flat top, and the variation in pulse to pulse voltage was minimized and hence, the energy provided to each volume of liquid is highly uniform. Ohmic heating caused by the low voltage associated with other types of pulses is minimised.

The pulse generator is composed of $D C$ power supply that charges an energy storage component and 31 identical modules, each module includes a set of four switches designed using Insulated Gate Bipolar Transistors (IGBTs). The switches operates in pairs for opening and closing periodically to discharge the current stored in the energy storage component, where the bipolar pulses across the treatment chamber can be provided. The generator also includes an input transformer and a rectifier designed to raise the voltage to $1.0 \mathrm{kV}$ and another transformer to increase the output voltage to $30 \mathrm{kV}$. The output voltage is varied by a variac (TSL Transformer specialties) connected to the high voltage generator. The voltage across the electrical pulse delivery system is measured by a DC voltmeter connected to a DC bus bar. The output current is measured using Rogowski coil (C2G, $400 \mathrm{w} / 50-60 \mathrm{~Hz}$ ) and an oscilloscope is used to illustrate the pulse shape. The frequency of the output pulses is varied by usinga signal generator.

\subsection{Experimental Protocols}

Thermal assisted pulsed electric fields treatment was applied to SMUF of 50\% (wt/wt) concentration inoculated with Geobacillus sterothermophilus ATCC 10149 spores. Two litres of the suspension medium were first de-aerated and heated to $60{ }^{\circ} \mathrm{C}$ in a controlled temperature water bath, then pumped using a piston pump through a flow meter into the PEF treatment chamber, where it was subjected to the high voltage electric pulses. The treated suspension was pressurised to $3 \mathrm{~atm}$ during processing to prevent local evaporation as a result of the high temperature application, and also to prevent dielectric breakdown of gas bubbles entrapped in the liquid food flowing through the cavity of the treatment chamber.

The treated suspension leaving the treatment chamber passed through a cooling coil immersed in a controlled temperature refrigerated water bath to decrease its temperature to below $10{ }^{\circ} \mathrm{C}$ rapidly. In industrial application, the heat available in the treated stream should be used to preheat the feed to make the process energy efficient.

Different experiments were conducted to investigate the effect of different treatment conditions on the inactivation rate of Geobacillus sterothermophilus ATCC 10149 spores suspended in SMUF of $50 \% \mathrm{wt} / \mathrm{wt}$ concentration. All experiments were run in duplicate to ensure accuracy of results. Microbial suspensions at different flow ratesin the range 


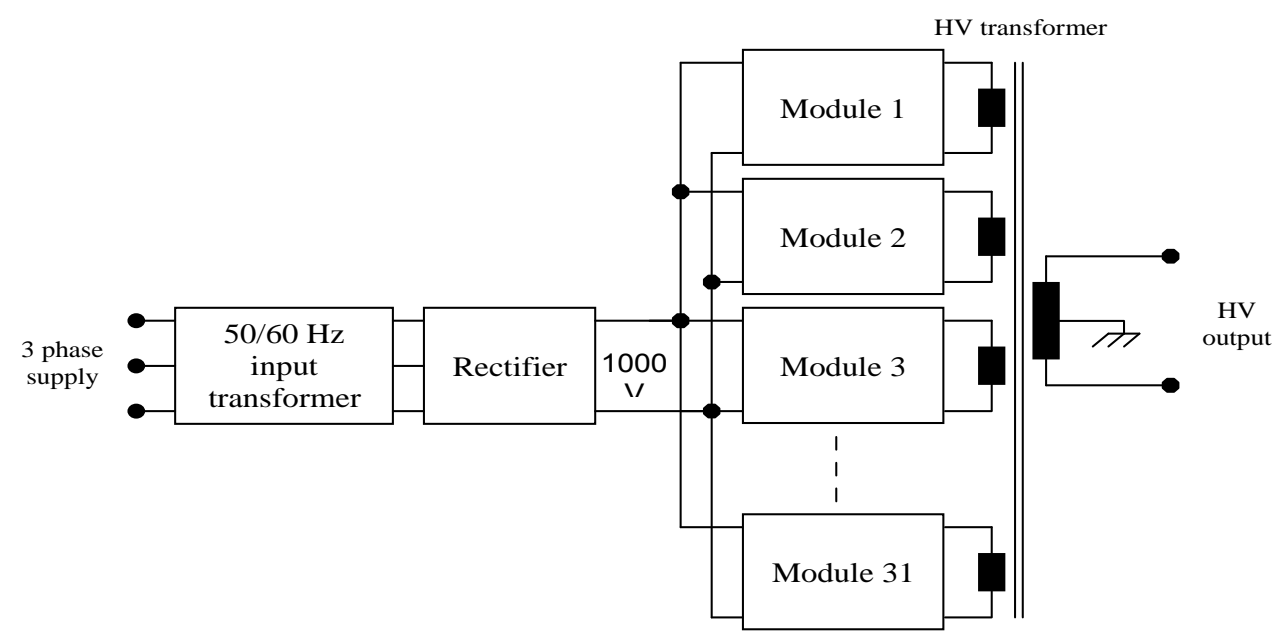

(a)

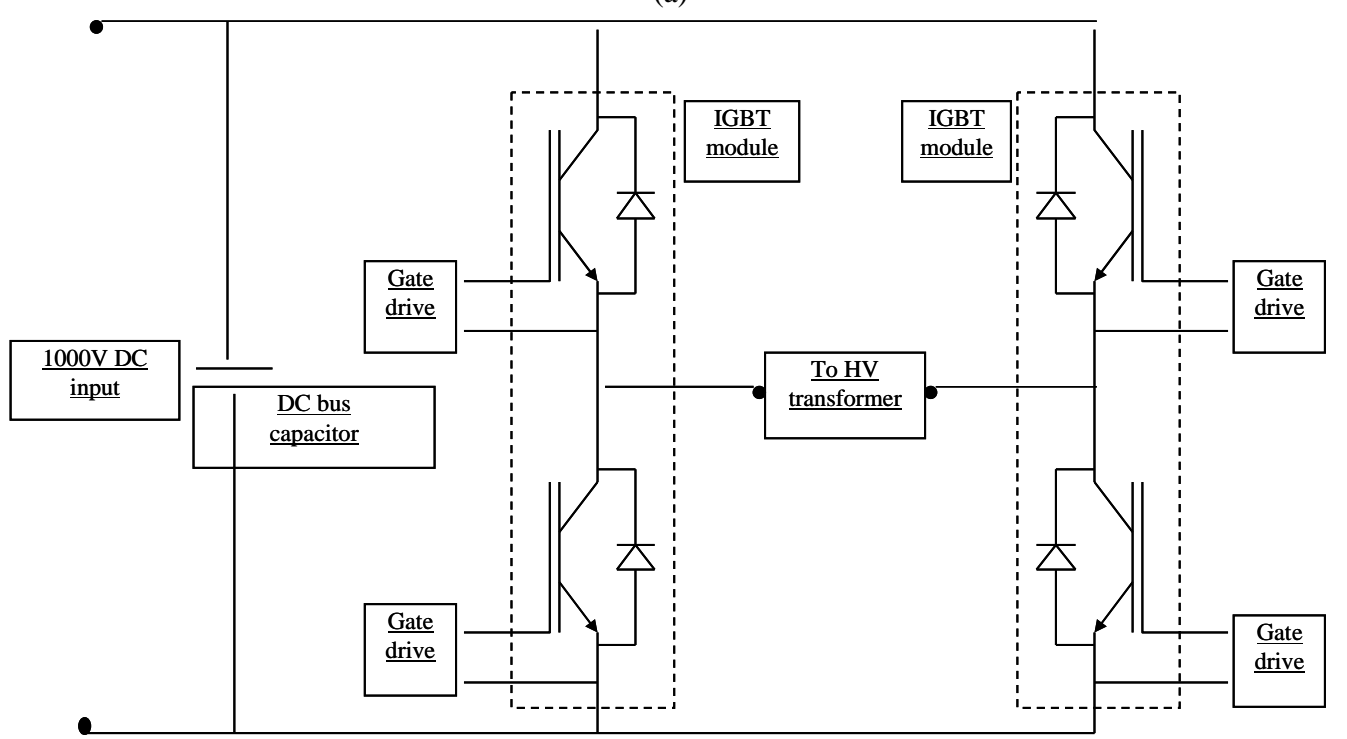

(b)

Fig. 3 (a) High voltage pulse generator, sketch of full system, (b) Sketch of each model (The University of Auckland, 2004).

of (3-6 mL/sec) and two different inlet temperatures (60 and $70^{\circ} \mathrm{C}$ ) were subjected to square bipolar pulses of $1.7 \mu$ s width and $1,000 \mathrm{~Hz}$ frequency at different electric field intensities (in the range of 37-45 kV/cm). Microbial load was measured before and after the PEF treatment to determine the effect of the different processing parameters on microbial inactivation.

Thermal inactivation experiments were also conducted to investigate the inactivation of Geobacillus sterothermophilus ATCC 10149 spores suspended in SMUF of 50\% wt/wt concentration. Samples of the microbial suspension were heated at different temperatures $\left(100-110^{\circ} \mathrm{C}\right)$ for various time intervals. Glass capillary tubes of $3 \mathrm{~mm}$ outside diameter and $1.2 \mathrm{~mm}$ inside diameter were sterilised before being filled with the microbial suspension. A sterilised syringe with an 18 gauge, $15 \mathrm{~cm}$ pipeting needle was used to add the suspension into the capillary tubes. The open end of the capillary tubes was heat sealed. Sets of capillary tubes were immersed in an oil bath circulator at a preselected temperature. Tubes were then removed at different timesand cooled immediately in ice water bath to less than $3{ }^{\circ} \mathrm{C}$. Following that the capillary tubes were washed with 70\% ethyl alcohol and both ends were cut aseptically to remove the sample. Suspension 
samples were analysed for microbial inactivation using the BacTrac measuring technology. Prior to all experiments, the microbial suspension was pasteurised at a temperature of $80{ }^{\circ} \mathrm{C}$ for $10 \mathrm{~min}$ to eliminate all vegetative cells.

\section{Results and Discussion}

Although increasing the electric field intensity increases microbial inactivation as reported previously by many researchers [2, 12, 15-18], spores of Bacillus thermophilus, cereus and polymyxa were reported resistant even when subjected to electric field of 30 $\mathrm{kV} / \mathrm{cm}[4,8,11]$. The results of the work presented in this paper conforms that applying PEF-ATS treatment is effective in the inactivatation of microbial spores. The microbial inactivation results as illustrated in Fig. 4, shows $0.9,1.8$ and $3.3 \log$ cycles reduction when applying electric field intensities of 34, 39 and 45 $\mathrm{kV} / \mathrm{cm}$ respectively, the outlet temperatures were 97 , 100 and $105^{\circ} \mathrm{C}$ respectively when the suspension inlet temperature was $60^{\circ} \mathrm{C}$ and the flow rate was $5 \mathrm{~mL} / \mathrm{sec}$. The corresponding Decimal Reduction Time $(D)$ were 4.1, 2.05, 1.12 sec respectively. Microbial reductions of 1.9, 2.6 and $4.1 \log$ cycles were achieved when the suspension inlet temperature was increased to $70{ }^{\circ} \mathrm{C}$ and applying electric field intensity of 35,37 and 45 $\mathrm{kV} / \mathrm{cm}$ respectively. The corresponding outlet temperatures were 107,108 and $115{ }^{\circ} \mathrm{C}$ and the $D$ values were 1.9, 1.4 and $0.9 \mathrm{sec}$ respectively. The treatment time inside the treatment chamber was $0.0213 \mu$ s corresponding to 12.5 pulses that the microbial suspension received. The residence time that the suspension spent inside the treatment chamber and the connecting tubes before being cooled was 3.7 s. Spores inactivation can be attributed to the effect of the elevated treatment temperature as well as the high electric field. The highest treatment temperature recorded was $115^{\circ} \mathrm{C}$, which is lower than the lethal temperature for spores if temperature is used alone, and hence the thermal damages to food can be prevented. The results show that this unique application decreased the $D$ values of $G$. stearothermophilus spores suspended in SMUF in comparison to thermal treatment alone.

Treatment time was increased by reducing the suspension flow rate, which in turn increases the number of pulses. Spores inactivation shows 1.7, 1.8, 1.9, 2.3 and $2.6 \log$ cycle reduction when using suspension flow rates of 5, 4.7, 4.1, 3.9 and 3.6 $\mathrm{mL} / \mathrm{sec}$ respectively corresponding to treatment times of 3.712, 3.713, 3.715, 3.716 and 3.717 sec respectively at constant pulse frequency of $1,000 \mathrm{~Hz}$ and electric field intensity of $37 \mathrm{kV} / \mathrm{cm}$ and inlet temperature of $70{ }^{\circ} \mathrm{C}$, as illustrated in Fig. 5. The treatment time was calculated based on the residence time inside the treatment chamber and the time that the liquid spent flowing in the pipe until its temperature was cooled down to below $50{ }^{\circ} \mathrm{C}$. The enchantment of microbial inactivation by increasing the treatment time was reported by many researchers [18-20]. However, Aronsson, Lindgren, Johansson \& Ronner [17] suggested that the microbial reduction caused mostly by the first pulse applied, each additional pulse had a less killing effect than the previous one.

Thermal inactivation experiments of $G$. sterothermophilus spores suspended in SMUF of 50\% (wt/wt) concentration shows no microbial inactivation during the first 5 minutes of treatment at the temperatures in the range of $100-115{ }^{\circ} \mathrm{C}$. For thermal treatment, Wimalaratne and Farid [21] and Shibeshi and Farid [18] reported $D$ values, for the same $G$. stearothermophilus ATCC 7953 suspended in UHT milk and soup, around $10 \mathrm{~min}$ at a temperature of $115^{\circ} \mathrm{C}$, which is 100 times bigger than the $D$ values obtained using PEF-ATS treatment. This suggests that the use of PEF in combination with thermal treatment can lower treatment temperature/time significantly providing benefits to food quality. The $D$ values obtained in this recently developed PEF-ATS is also lower than that found in pressure assisted sterilization, making it very attractive technology for sterilization 


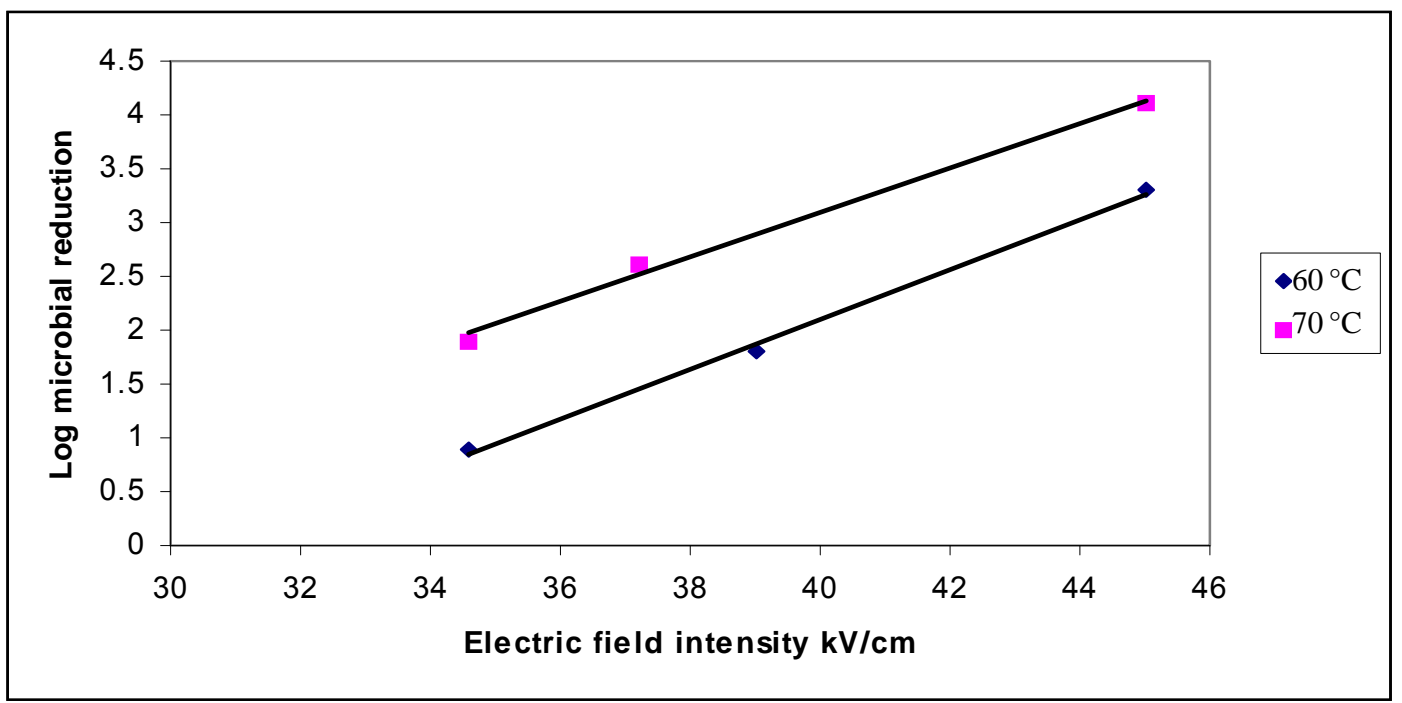

Fig. 4 Effect of different electric field strength and inlet temperature on G. sterothermophilis spores inactivation using the TAPEF technology.

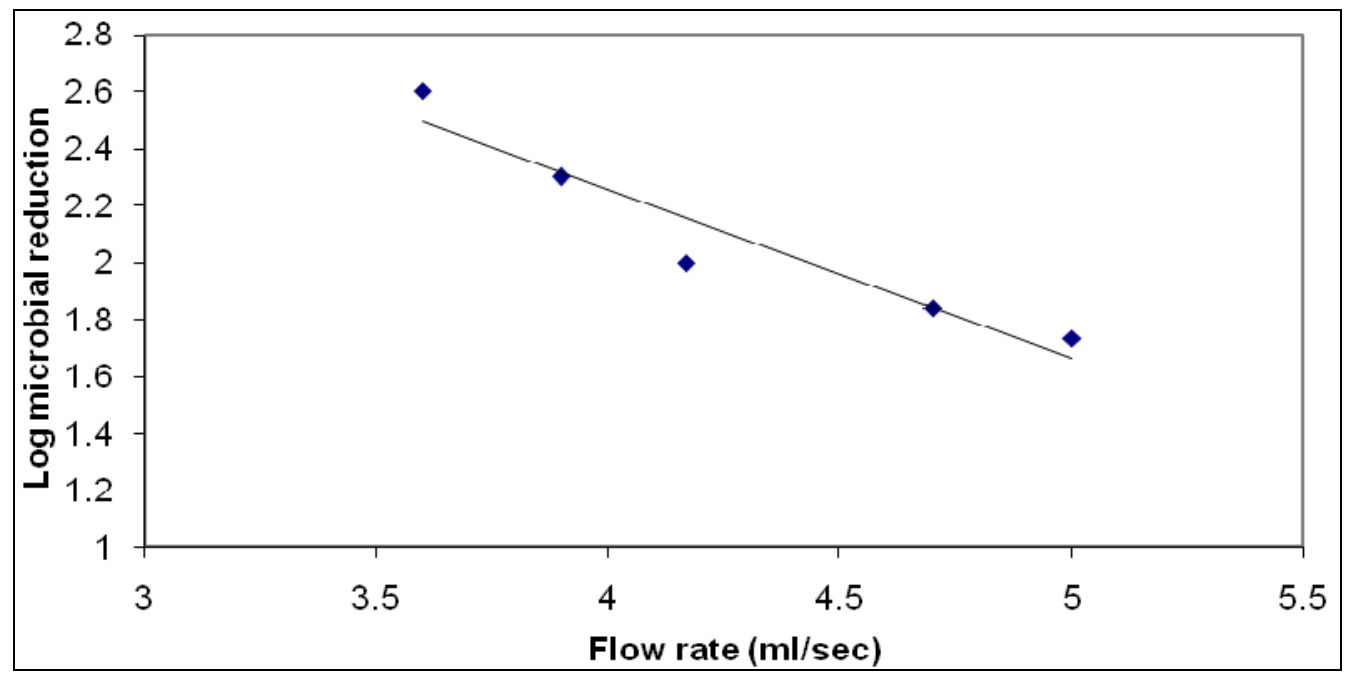

Fig. 5 Effect of using different suspension flowrates on $G$. sterothermophilus spores inactivation when subjected to electric field intensity of $37 \mathrm{kV} / \mathrm{cm}$, frequency of $1,000 \mathrm{~Hz}$ and inlet temperature of $70^{\circ} \mathrm{C}$ using the TAPEF technology.

of pumpable food products. Ahn, Balasubramaniam and Yousef [15], reported that pressure assisted thermal processing (PATP) shows more than 2 log spore/mL of $T$. thermosaccharolyticum survived after 5 min treatment at $105{ }^{\circ} \mathrm{C}, 700 \mathrm{MPa}$, while $\mathrm{T}$. thermosaccharolyticum spore population required severe PATP treatment of $121^{\circ} \mathrm{C}, 700 \mathrm{MPa}$ for $1 \mathrm{~min}$ for complete inactivation.

\section{Conclusions}

The innovative thermal assisted pulsed electric field PEF-ATS processing is a promising technology for the inactivation of microbial spores. The technology confirms the enhancement of Geobacillus sterothermophilus spores inactivation at lower time/ temperature conditions than thermal processes, reducing the sterilisation temperature provides consumers with microbiological safe and nutritious, fresh like foods. Microbial inactivation increased with the increase in the electric field strength and processing temperature conforming that the combined effect enhanced the inactivation. Increasing the treatment time also shows increasing in the efficiency of the spore inactivation. 


\section{References}

[1] P.M. Periago, P.S. Fernandez, M.J. Ocio, A. Martinez, Apparent thermal resistance of Bacillus stearothermophilus spores recovered under anaerobic conditions, Zeitschriftfür Lebensmitteluntersuchung und -Forschung A 206 (1998) 63-67.

[2] L.D. Reina, Z.T. Jin, Q.H. Zhang, A.E. Yousef, Inactivation of listeria monocytogenes in milk by pulsed electric field, Journal of Food Protection 61 (9) (1998) 1203-1206.

[3] M.C. TeGiffel, A. Wagendorp, A. Herrewegh, F. Driehuis, Bacterial spores in silage and raw milk, Antonie Van Leeuwenhoek 81 (2002) 625-630

[4] W. Chen, R. Lee, Altered ion channel conductance and ionicselectivity induced by large imposed membrane potential pulse, Biophysics Journal 67 (1994) 603-612.

[5] B. Mazurek, P. Lubicki, Effect of short HV pulses on bacteria and fungi, IEEE Transactions on Dielectric and Electrical Insulation 2 (3) (1995) 418-424.

[6] S. Jayaram, G.S.P. Castle, Kinetics of sterilization of Lactobacillus brevis cells by the application of high voltage pulses, Biotechnology and Bioengineering 40 (1992) 1412-1420.

[7] R. Jeantet, F. Baron, F. Nau, M. Roignant, G. Brule, High intensity pulsed electric fields applied to egg white: Effect of Salmonella enteritidis inactivation and protein denaturation, Journal of Food Protection 62 (12) (1999) 1381-1386.

[8] V.O. Marquez, G.S. Mittal, M.W. Griffiths, Destruction and inhibition of bacterial spores by high voltage pulsed electric field, Journal of Food Science 62 (2) (1997) 213-437.

[9] Y. Yin, Q.H. Zhang, S.K. Sastry, High voltage pulsed electric field treatment chambers for the preservation of liquid food products, US Patent, 5690978, 1997.

[10] S. Alkhafaji, M. Farid, An investigation on pulsed electric fields technology using new treatment chamber design, Innovative Food Science and Emerging Technologies 8 (2) (2006) 205-212.

[11] U.R. Pothakamury, A. Monsalvegonzalez, G.V. Barbosa-Ca`novas, B.G. Swanson, Inactivation of
Escherichia coli and Staphylococcus aureus in model foods by pulsed electric field technology, Food Research International 28 (2) (1995) 167-171.

[12] S. Ravishankar, G. Fleischman, V. Balasubramaniam, The inactivation of Escherichia coli O157:H7 during pulsed electric field (PEF) treatment in a static chamber, Food Microbiology 19 (4) (2002) 351-361.

[13] S. Alkhafaji, An investigation on the non thermal pasteurization using pulsed electric fields, Ph.D. Thesis, University of Auckland, 2006.

[14] Alvarez, J. Virto, J. Raso, S. Condón, Comparing predicting models for the Escherichia coli inactivation by pulsed electric fields, Innovative Food Science \& Emerging Technologies 4 (2003) 195-202.

[15] J. Ahn, V.M. Balasubramaniam, A.E. Yousef, Inactivation kinetics of selected aerobic and anaerobic bacterialspores by pressure-assisted thermal processing, International Journal of Food Microbiology 113 (3) (2007) 321-329.

[16] P.C. Wouters, J.P.P.M. Smelt, Inactivation of microorganisms with pulsed electric fields: Potential for food preservation, Food Biotechnology 11 (3) (1997) 193-229.

[17] K. Aronsson, M. Lindgren, B.R. Johansson, U. Ronner, Inactivation of microorganisms using pulsed electric fields: The influence of process parameters on Escherichia coli., Listeria innocua, Leuconostocmesenteroides and Saccharomyces cerevisiae, Innovative Food Science \& Emerging Technologies 2 (2001) 41-54.

[18] K. Shibeshi, M. Farid, Scale-up unit of a unique moderately high pressure unit to enhance microbial inactivation, Journal of Food Engineering 105 (3) (2011) 522-529.

[19] G.V. Barbosa-Canovas, M.M. Gongora-Nieto, U.R. Pothakamury, B.G. Swanson, Preservation of Foods with Pulsed Electric Fields, Academic Press, USA, 1999.

[20] D. Knorr, M. Geulen, T. Grahl, W. Sitzman, Food application of high electric field pulses, Trans in Food Science \& Technology 5 (1994) 71-75.

[21] S.K. Wimalaratne, M.M. Farid, Pressure assisted thermal sterilization, Food Bioproducts Process 86 (2008) 312-316 